\title{
The Difficult Items in the TGMD-2 and BOT-2 for Taiwanese Preschoolers
}

\author{
Shu-Chu Yang ${ }^{1}$, Shu-Jung Lin ${ }^{2, *}$, Hsin-Ying Chang ${ }^{1}$, I-Tso Chien ${ }^{1}$ \\ ${ }^{1}$ Department of Early Childhood Education, National Chiayi University, Taiwan \\ ${ }^{2}$ Department of Early Childhood Education, Nanhua University, Taiwan
}

Received July 26, 2020; Revised November 25, 2020; Accepted December 6, 2020

\begin{abstract}
Cite This Paper in the following Citation Styles
(a): [1] Shu-Chu Yang, Shu-Jung Lin, Hsin-Ying Chang, I-Tso Chien, "The Difficult Items in the TGMD-2 and BOT-2 for Taiwanese Preschoolers," International Journal of Human Movement and Sports Sciences, Vol. 8, No. 6, pp. 518-524, 2020. DOI: 10.13189/saj.2020.080626.
\end{abstract}

(b): Shu-Chu Yang, Shu-Jung Lin, Hsin-Ying Chang, I-Tso Chien (2020). The Difficult Items in the TGMD-2 and BOT-2 for Taiwanese Preschoolers. International Journal of Human Movement and Sports Sciences, 8(6), 518-524. DOI: 10.13189/saj.2020.080626.

Copyright $\bigcirc 2020$ by authors, all rights reserved. Authors agree that this article remains permanently open access under the terms of the Creative Commons Attribution License 4.0 International License

\begin{abstract}
The main purpose of this research was to determine which items in the Test of Gross Motor Development, Second Edition(TGMD-2) and Bruiniks-Oseretsky test of motor proficiency, with which Second Edition (BOT-2) preschoolers have difficulty. The methodology consisted of qualitative research. We used two motor skill testing and observation children's motor skill. The participants were 40 preschoolers, 20 participants were 48 months through 59 months of age, and the other 20 participants were 60 months through 78 months of age, all of whom completed both of these standardized tests. The findings were as follows: For TGMD-2, in galloping, the 1st group participants lacked a coordinated stride. Over 85 percent of all children were unable to transfer body weight to the front foot. Around 70 percent of the 1st group were unable to push a ball with their fingertips, and 65 percent of the 1st group were unable to maintain control of a ball for four consecutive bounces without having to move their feet to retrieve it. For BOT-2, all children had difficulty copying a five-pointed star and dribbling a ball with alternating hands. Around 95 percent of the 1st group participants were unable to do the knee push-ups, and 42 percent of them were unable to do sit-ups. It is recommended that preschool teachers should design low structured ball activities, which kids enjoy playing due to the lack of formal instruction. Moreover, instructions and demonstrations should be given in a lively manner, so as to make the activity more appealing. Finally, in light of the difficulties, Taiwanese preschoolers have with several
\end{abstract}

of the items (dribbling, dribbling with alternate hands, etc.), we recommend that the scoring criteria be minorly adjusted based on the results of same test administered in various countries.

Keywords Difficult Items, TGMD-2, BOT-2

\section{Introduction}

Steady advances in technology have brought about many benefits the world over, but are also a major cause of reduced physical activity. Even in our near surroundings, we can turn on/off electronic devices with the "help" of our fingers. Actually, much of what we used to do by using whole body movements, nowadays, we just use the hands or even the fingers [1]. In modernized nations like Taiwan the problem is exacerbated by the excessive emphasis given to students' academic performance, which typically begins right from preschool. Additional factors militating against Taiwanese preschoolers getting sufficient exercise are the lack of open spaces in urban areas, overworked parents with little time for outdoor activities, and an educational environment which gives little importance to physical development. Numerous studies have shown that early childhood is the critical period for the development of fundamental movement skills (FMS), which in turn 
facilitates the development of neuromuscular coordination, emotional maturity, and interpersonal skills [2-5]. Moreover, the acquisition of FMSs is a prerequisite for the development of various types of advanced movement skills.

The current trend continues unabated, and studies have shown that the FMSs of Taiwanese preschoolers and grade-schoolers lag behind those of their counterparts in Hong Kong, and the USA [6,7]. But preschoolers on the Taquile and Amantaní islands have a higher OCMD than those U.S. children, because their islands are surrounded by natural spaces and resources, which allows them to interact effectively and efficiently with objects spontaneously. However, in the United States, children live in an increasingly artificialized environment, an environment that generates little active behavior [8-9]. Motor development is influenced by many factors such as environment, practice and appropriate instruction, provided by teachers, even in preschool and elementary school [1,9].

To mitigate this problem in Taiwan, in 2012 the Ministry of Education added " 30 minutes per day of vigorous exercise" to the list of items for evaluating kindergartens, and its preschool curriculum promulgated in 2017 recognizes the importance of FMSs as the basis of overall good health [10].

According to Wilson, amongst the existing tools for testing FMSs, the Bruininks-Oseretsky Test of Motor Proficiency-2 (BOT-2) is most widely used in North America, and the Movement ABC-2 is the preferred test in Europe and Asia [11]. In addition, many researchers in Asia, the United States, and Australia have used the Test of Gross Motor Development-2 (TGMD-2) [12-14]. Previous related studies have mostly used a single test tool, and have focused on such factors as gender, age, body mass index (BMI), reliability, validity, and curriculum integration [15-21]. In our previous studies in this area, we used the TGMD-2, and found that children aged 3-6 years were less developed in object manipulation skills than in locomotor skills. Our results included the means, $\mathrm{t}$-values, and f-values for each test item, but we failed to make a detailed description of the testing criteria for each item, nor did we specify which of these criteria the participants had the most difficulty with; thus, we failed to provide specific suggestions as to exactly how the participants might improve their performance. The purpose of the present study is to remedy these shortcomings by making a detailed analysis of the testing criteria for each item and making concrete suggestions for improving the participants' performance. With this purpose in mind, it was determined that the Movement ABC-2 would be unsuitable for this study, since the evaluation for each item is based merely on the presence or absence of certain actions, without considering whether or not each one is correctly performed.

\section{Materials and Methods}

Purposive sampling was used to recruit a suitable preschool for inclusion in this study, and testing and observation were used to gather the data.

\subsection{Participants}

The participants were 40 good health children between the ages of 4 and 6, divided into two age groups: 20 participants were 48 months through 59 months of age, who were tested in the first week of the month, which refers to the $1^{\text {st }}$ group. And the other 20 participants were 60 months through 78 months of age, who were tested in the next week, which refers to the $2^{\text {nd }}$ group. This preschool used to have 30 minutes of sweaty gross motor activity designed for children every day.

\subsection{Description of the Testing Tools}

Mainly developed by Ulrich \& Sanford, the TGMD-2 tests six locomotor skills (Run, Gallop, Hop, Leap, Horizontal Jump, and Slide) and six object control skills (Striking a Stationary Ball, Stationary Dribble, Catch, Kick, Overhand Throw, and Underhand Roll) [22]. This test is designed for use with children aged 3-10 and has been found to have good reliability and validity (The internal consistency is .85 , and the test-retest is $.98 ; \chi^{2}$ $=280.3 ; \mathrm{GFI}=.96 ; \mathrm{AGFI}=.95)[22]$. As an example of the scoring method for object control skills, catching consists of three movements; performance of each movement earns the participant one point. 1. Preparation phase where hands are in front of the body and elbows are flexed, 2. Arms extend while reaching for the ball as it arrives, 3 . Ball is caught by hands only, each participant is tested twice for each item, and the final score is the sum of these two trials (i.e., the score is between 0 and 6). In our data and samples, the internal consistency reliability is .83 . Materials include 8-to10-inch playground ball, 4-inch lightweight ball, basketball, tennis ball, soccer ball, softball, 4-to 5-inch square beanbag, tape, 2 traffic cones, plastic bat and batting tee.

The BOT-2 was developed by Bruininks and is suitable for ages 4-21. This test tool has a full version (53 test items) and a short form. The short form tests five fine motor skills (Drawing Lines through Paths-Crooked, Folding Paper, copying a Square, Coping a Star, Transferring Pennies) and nine gross motor skills(Jumping in Place-Same Sides Synchronized, Tapping Feet and Fingers-Same sides Synchronized, Walking Forward on a Line, Standing on One Leg a Balance Beam-Eyes Open, One-Legged Stationary Hop, Dropping and Catching a Ball-Both Hands, Dribbling a Ball-Alternating Hands, Knee Push-ups, Sit-ups). For both the full version and the short form, the reliability of all the items is above .70. We used the short form for testing. 
In the BOT-2, the raw scores have to be converted. For example, in the item Transferring Pennies, the participants are given two 15 -second periods to toss as many pennies as they can into a receptacle. For example, if nine coins are tossed into the receptacle in the first trial, and ten in the second, then the final score is 9-10, and on the comparison, table the score is 4. Bot-2 materials and equipment include Manual, Examinee booklets, blocks, cards, pennies, red pencils, shuttle block, target, Administration easel, record forms, balance beam, box, knee pad, penny pad, Scissors, string, Tennis ball, stopwatch, a tape measure, a table, and two chairs.

\subsection{Testing Procedures}

The tests were conducted by three groups of testers; each group consisted of two members, one to demonstrate and explain each item, and one to do the scoring. The testers had all completed coursework in games and physical skills at university or graduate school, and were trained in using the testing tools, arranging the testing area, and safety measures. All of the testers watched a training video, and the inter-rater reliability was .90 . All of the participants were tested individually, with two children present at a time, so as to increase the participants' sense of safety. The test was completed in 15-20 minutes.

\subsection{Data Analysis}

The Statistical Package for the Social Sciences (SPSS) for windows, version 24.0, was used to compile the data. The percentages were used to analyze the successful or failing of the participant's motor skill. In the video recording, it can be seen that those participants performed the motor skill's posture. We also used the Cronbach's alpha for the internal consistency reliability.

\section{Results and Discussion}

\subsection{TGMD-2}

Gallop: More than $90 \%$ of the participants aged 60 months through 78 months (refers to the $2^{\text {nd }}$ age group) completed this item satisfactorily. But for the 48 months through 59 months (refers to the $1^{\text {st }}$ age group) the success rate was only $65 \%$, since many were unable to maintain a rhythmic pattern for four consecutive gallops and a step forward with the lead foot followed by a step with the trailing foot to a position adjacent to or behind the lead foot.

These findings are similar to this found by Ulrich (2000) in American preschoolers (between four and five years old) [22]. In the video recording, it can be seen that many were unable to perform the coordinated action, because this movement is more difficult and it requires coordination throughout the body [23]. There is no difference in galloping performance between the preschoolers (between four and five years old) in Taiwan and American.

Striking a stationary ball: For the $1^{\text {st }}$ age group, only $40 \%$ of the participants rotated the hips and shoulders while swinging the bat, and $60 \%$ of the participants failed to satisfactorily rotate the hips and shoulders while swinging the bat. This finding is similar to this found by Ulrich (2000) [22]. 100\% of those in the $1^{\text {st }}$ age group and $85 \%$ of those in the $2^{\text {nd }}$ age group failed to satisfactorily transfer their body weight to the front foot. In the video recording, it can be seen that they were only moving their arms, without turning their shoulders or hips, and without shifting their center of gravity. The participants' difficulty with this item was largely due to the fact that it was completely new to them. As suggested by Tseng and Chiu, this difficulty is also due to a relative inability to shift the center of gravity by rotating the feet, hips, and shoulders, all of which are required in both throwing and striking a stationary ball [24].

Stationary dribble: Only $30 \%$ of the the $1^{\text {st }}$ age group participants were able to push the ball with their fingertip, and $35 \%$ of the participants were able to maintain control of the ball for four consecutive bounces without having to move the feet to retrieve it. $70 \%$ of those in the $1^{\text {st }}$ age group were unable to push the ball with their fingertips, and $65 \%$ were unable to maintain control of the ball for four consecutive bounces without having to move the feet to retrieve it. These findings are similar to this found by Ulrich (2000) [22]. In the video recording, it can be seen that most of the participants used their palms to dribble the ball, making it difficult to control the amount of force applied to the ball and the direction of its movement. $\mathrm{Li}$ and Diao's participants also had difficulty with dribbling [13]. This deficit is mainly due to a lack of proper instruction and manipulative skills. Although the kindergarten provides balls to play with, the children are rarely provided with any instruction in how to dribble.

Underhand roll: Only $45 \%$ of the $1^{\text {st }}$ age group participants were able to use "preferred hand swings down and back," and $15 \%$ of the participants were able to "stride forward with foot opposite the preferred hand toward the cones." $55 \%$ of the participants in the $1^{\text {st }}$ age group failed on "preferred hand swings down and back," and $85 \%$ failed on "stride forward with foot opposite the preferred hand toward the cones." These findings are similar to this found by Ulrich (2000) [22]. In the video recording, it can be seen that the participants are typically standing with feet parallel, and without moving one foot forward when using one or both hands to roll the ball.

\subsection{BOT-2}

Copying a star: only $38 \%$ of the $1^{\text {st }}$ age group participants were able to draw the basic shape, closure, orientation, and oversize successfully. However, more 
than $80 \%$ of the $2^{\text {nd }}$ age group participants were able to draw the basic shape, closure, orientation, and oversize successfully. $62 \%$ in the $1^{\text {st }}$ age group and $10-20 \%$ in the $2^{\text {nd }}$ age group failed in terms of basic shape, closure, orientation, and oversize; $85 \%$ of all the participants were unable to draw the edges and $15 \%$ of all the participants were able to draw the edges. In the video recording, it can be seen that the participants' hand movements lack precision and that their posture is askew, making it difficult to properly copy the star. In addition, all of the participants had difficulty making each side equal in length, and many of those in the $\mathbf{1}^{\text {st }}$ age group used a fist to grip the pen rather than their fingers. Those in the $\mathbf{1}^{\text {st }}$ age group had the most difficulty making precise hand movements. Although most kindergartens in Taiwan include in their curriculum a variety of arts and crafts activities for the development of fine motor dexterity, these activities are allotted little time in the daily routine. The participants' difficulty with this item can also be explained by the fact that they are still in the preschematic stage of development, when rounded shapes are preferred and people are mainly represented in the form of stick figures. Moreover, the shapes used in preschool art instruction tend to consist of circles, squares, and triangles, rather than stars.

Dribbling ball-alternating hands: The participants in the $1^{\text {st }}$ age group had considerable difficulty performing this action; $42 \%$ couldn't do it at all, while the remaining $58 \%$ were able to do it $1-3$ times. Those in the $2^{\text {nd }}$ age group also had some difficulty; $80 \%$ were able to do it $1-$ 3 times, and the remaining $20 \%$ were able to do it $4-10$ times. In the video recording, it can be seen that most of the participants were unable to dribble with alternating hands, using one hand instead. Although the tennis ball used is small and bounces well, the participants had difficulty controlling its direction and the amount of force applied.

Knee push-ups: This action was to be completed in 30 seconds. $95 \%$ of those in the $\mathbf{1}^{\text {st }}$ age group failed to perform even one push-up, and the remaining $5 \%$ did one push-up. By contrast, $75 \%$ of those in the $2^{\text {nd }}$ age group did 11-20 push-ups. In the video recording, it can be seen that those in the $\mathbf{1}^{\text {st }}$ age group performed the preparation exercise quite well, but they lacked sufficient strength and stamina in the arms and shoulders required to perform the push-ups.

Sit-ups: This action was to be completed in 30 seconds. $42 \%$ of those in the 1st age group failed to perform even one sit-up, and the remaining $58 \%$ did $1-2$ sit-ups. By contrast, $60 \%$ of those in the $2^{\text {nd }}$ age group did 3-10 sit-ups, and the remaining $40 \%$ did $11-25$. This item requires making use of the abdominal muscles, which are not very developed in many preschoolers. Knee push-ups require strong arm and chest muscles, while sit-ups require strong abdominal muscles, all of which are normally only developed through specific training [25]. However, very few kindergarten teachers provide such training, in the belief that preschoolers are too young for such activities. Thus, Taiwanese children have much difficulty performing push-ups and sit-ups prior to the third grade. The study asserts that socialization and nature are the main factors affecting children's behavior, also, in the USA many kindergarten teachers punish unruly boys by having them run laps or do sit-ups or push-ups, indicating that these are familiar activities for American children [26]. By contrast, Taiwanese kindergarten teachers typically punish unruly children by having them run a single lap or stand facing the wall. Moreover, sit-ups and push-ups are rarely taught in Taiwanese preschools. 
Table 1. The Difficult Items

\begin{tabular}{|c|c|c|}
\hline The Difficult Items & $\begin{array}{l}\text { Group1: aged } 48 \text { months } \\
\text { through } 59 \text { months }\end{array}$ & $\begin{array}{l}\text { Group2: aged } 60 \text { months } \\
\text { through } 78 \text { months }\end{array}$ \\
\hline \multicolumn{3}{|l|}{ TGMD-2 } \\
\hline \multicolumn{3}{|l|}{ Gallop } \\
\hline $\begin{array}{l}\text { A step forward with the lead foot followed by a step with the trailing foot } \\
\text { to a position adjacent to or behind the lead foot }\end{array}$ & $65 \%$ & More than $90 \%$ \\
\hline Maintain a rhythmic pattern for four consecutive gallops & $65 \%$ & More than $90 \%$ \\
\hline \multicolumn{3}{|l|}{ 2. Striking a stationary ball } \\
\hline Hip and shoulder rotating during swing & $40 \%$ & $60 \%$ \\
\hline Transfer their body weight to the front foot & $0 \%$ & $15 \%$ \\
\hline \multicolumn{3}{|l|}{ 3. Stationary dribble } \\
\hline Push ball with fingertips & $30 \%$ & $60 \%$ \\
\hline $\begin{array}{l}\text { Maintain control of ball for four consecutive bounces without having to } \\
\text { move the feet to retrieve it }\end{array}$ & $35 \%$ & $60 \%$ \\
\hline \multicolumn{3}{|l|}{ 4. Underhand roll } \\
\hline Preferred hand swings down and back & $45 \%$ & $65 \%$ \\
\hline Stride forward with foot opposite the preferred hand toward the cones. & $15 \%$ & $60 \%$ \\
\hline \multicolumn{3}{|l|}{ BOT-2 } \\
\hline \multicolumn{3}{|l|}{ 1. Copying a star } \\
\hline Draw the basic shape, closure, orientation, and oversize successfully & $38 \%$ & more than $80 \%$ \\
\hline Draw the edges & $15 \%$ & $15 \%$ \\
\hline \multicolumn{3}{|l|}{ 2. Dribbling a ball-alternating hands } \\
\hline $1-3$ times & $58 \%$ & $80 \%$ \\
\hline $4-10$ times & $20 \%$ & $20 \%$ \\
\hline 3. Knee push-ups (in 30 seconds) & $5 \%$ one push-up & $75 \% 11-20$ push-ups \\
\hline 4. Sit-ups (in 30 seconds) & $58 \% 1-2$ sit-ups & $\begin{array}{l}60 \% 3-10 \text { sit-ups } \\
40 \% 11-25 \text { sit-ups }\end{array}$ \\
\hline
\end{tabular}

In summary, when being tested on Dribbling in both the TGMD-2 and the BOT-2, a large proportion of Taiwanese preschoolers have considerable difficulty controlling the amount of force applied to the ball and its direction. Dribbling a small ball, such as a tennis ball, is done with the palm, while dribbling a large ball, such as a basketball, is done with the fingertips. However, preschoolers tend to always use their palms to dribble, and typically apply excessive force, which makes it difficult to control the ball. Also, most preschoolers are used to dribbling with either one hand or with two hands joined together; very few have ever dribbled with alternating hands, and thus have much difficulty with this item. As for Striking a Stationary Ball and Underhand Roll, both require shifting the center of gravity, and the latter requires moving one foot forward. Such movement skills are entirely unfamiliar to the average Taiwanese preschooler, so it's not surprising that they have much difficulty with these two items.

It is possible that children with good copying skills have developed another underlying cognitive process that allows them to achieve at higher levels. For example, a child with strong fine motor and copying skills may have better "automaticity," which means he or she can easily perform basic motor tasks like getting ready to write letters on a piece of paper. If so, this might free up cognitive resources for learning more complex skills, like reading whole words, and writing [27].

In terms of hand dexterity training, Taiwanese kindergartens focus on the techniques of tearing, pasting, cutting, twisting, and kneading; in drawing, the emphasis is on imagination, and preschoolers are rarely required to draw uniform shapes of a particular size. Thus, many have difficulty copying a star, especially those in the $\mathbf{1}^{\text {st }}$ age group. It is possible that children with good copying skills have developed another underlying cognitive process that allows them to achieve at higher levels. For example, a child with strong fine motor and copying skills may have better "automaticity," which means he or she can easily perform basic motor tasks like getting ready to write letters on a piece of paper. If so, this might free up cognitive resources for learning more complex skills, like reading whole words, and writing [27].

Therefore, it is suggested that kindergarten teachers might want to organize a semester-long PE course including various types of dribbling and exercises which strengthen the fingers, arms, shoulders, and abdomen. In addition to teaching preschoolers proper techniques for 
use in ball games and basic safety, such a course would go a long way in expanding the teacher's repertoire of $\mathrm{PE}$ activities.

\section{Conclusions}

The results of this study suggest that Taiwanese preschools need to provide children with additional opportunities to play ball games, and design some physical fitness suitable for young children (although the current situation in Taiwan is that academic experts in early childhood education still discourage physical fitness for young children). We also need to give the natural spaces and resources for children to play. However, all providing activities need to be fun and not overly structured. In addition, the teacher needs to adopt a friendly and playful attitude when providing instructions and demonstrations, since this will help the children to enjoy the activities and regard them as competitive game, rather than as training or a test. In addition, the main reason Taiwanese preschoolers have considerable difficulty performing a number of the items in the TGMD-2 and the BOT-2 is the differences of the environment between Taiwan, Peru, and the West. Taiwanese preschoolers have limited play space for children to play actively, and teachers lack ball games and children's physical fitness skills and training. These problems deserve the attention of the Taiwan authorities.

\section{REFERENCES}

[1] Barela, J. A. (2013). Fundamental motor skill proficiency is necessary for children's motor activity inclusion. Motriz. Revista de Educacao Fisica, 19(3), 548-551.

[2] Yu, Y.T., \& Chou, H.S. (2014). Movement Development on Young Children in the Perspective of Autonomic Nervous System. Journal of National Cheng Kung University Physical Education Research, 46(1), 34-48.

[3] Pang, A. W. Y., \& Fong, D. T. P. (2009). Fundamental motor skill proficiency of Hong Kong children aged 6-9 years. Research in Sports Medicine, 17(3), 125-144.

[4] Sun, S. H., Zhu, Y. C., Shih, C. L., Lin, C. H., \& Wu, S. K. (2010). Development and initial validation of the preschooler gross motor quality scale. Research in Developmental Disabilities, 31(6), 1187-1196.

[5] Sheikh, M., Safania, A. M., \& Afshari, J. (2011). Effect of selected motor skills on motor development of both genders aged 5 and 6 years old. Procedia Social and Behavioral Sciences, 15, 1723-1725.

[6] Lin, S. J. (2014). Study on the development of three to nine-year-old children's fundamental movement skills and norms construction in Chiayi Area (Unpublished doctoral dissertation). National Chiayi University, Chiayi City.
[7] Yang, S. C., Chang, C.M., \& Tsai, C.Y. (2014). Fundamental Movement Skill Development with Preschool Children in Taiwan. Retrieved from https://www.grb.gov.t $\mathrm{w} / \mathrm{search} /$ planDetail $\mathrm{id}=8014545$

[8] Mamani-Ramos, A.A., Dextre-Mendoza, C.W., Lava Galvez, J. J., Flores, G. T., Quispe Cruz, L.M., Torres-Cruz, F., Quisocala Mamani, J. A., \& Fuentes-Lopez, J. D. (2021). Gross motor development in preschoolers on the islands of Lake Titicaca (3810 m.a.s.1.), Puno, Peru. Retos, 39, 592-597.

[9] Castell, C. (2020). Nature and health: a necessary alliance. GacetaSanitaria, 34(2), 194-196.

[10] Early Childhood Educare (2019). ECEC curriculum framework (Taiwan, R.O.C.). Retrieved fromhttps://www.e ce. moe.edu.tw/wp-content/uploads/

[11] Wilson, B.N., Kaplan, B. J., Crawford, S. G., Campbell, A., \& Dewey, D. (2000). Reliability and validity of a parent questionnaire on childhood motor skills. American Journal of Occupational Therapy, 54, 484-493.

[12] Mulvey, K. L., Miedema, S.T., Stribing, A., Gilbert, E., \& Brian, A. (2019). SKIPing Together: A Motor Competence Intervention Promotes Gender-Integrated Friendships for Young Children. Retrieved from https://link.springer.com/a rticle/10.1007/s11199-019-01079-z

[13] Diau, Y.C., Li, J. (2013). Comparative study of motor skills aged from 3 to 10 years old in Jinan. Shandong Sports Science \& Technology, 3,114-118.

[14] Hardy, L. L., King, L., Farrell, L., Macniven, R., \& Howlett, S. (2010). Fundamental movement skills among Australiam preschool children. Journal of Science and Medicine in Sport, 13(5), 503-508.

[15] Lin, S. J., \& Yang, S. C. (2015). The development of fundamental movement Skills by children aged six to nine. Universal Journal of Educational Research, 3(12),1024-10 27.

[16] Yang, S.C., Lin, S.J., \&Tsai, C.Y., (2015). Effect of sex,age,amd BMI on the development of locomoter skills and object control skills among preschool children. Perceptual and Motor Skills, 121, 1-16.

[17] Samara, D., Sidarta, N., Mediana, D., \& Noviyanti. (2012). Gender impacts on motor skill proficiency-physical activity relationship in children. Universa Medicina, 31(3), 192-199.

[18] Engel-Yeger, B., Rosenblum, S., \& Josman, N. (2010). Movement Assessment Battery for Children (M-ABC): Establishing construct validity for Israeli children. Res Dev Disabil, 31(1), 87-96.

[19] Tsai, C.L. (2015). An Analysis on Reliability, Validity and Norm of the Movement $A B C-2$ for children aged 3-6 years. (Unpublished doctoral dissertation) University of National Chia-Yi, Chia-Yi.

[20] Kim, S., Kim, M.J., Valentini, N.C., \& Clark, J. E. (2014). Validity and reliability of the TGMD-2 for South Korean children. Journal of Motor Behavior, 46(5), 351-356.

[21] Fransen, J. U., D’Hondt, E. Bourgois, J. Vaeyens, R., Philippaerts, R. U., \& Lenoir, M. (2014). Motor competence assessment in children: convergent and discriminant validity between the BOT- 2 Short Form and KTK testing batteries. 
Research in Development Disabilities, 35(6), 1375-1383.

[22] Ulrich, D. A., \& Sanford, C. B. (2000). Test of gross motor development: Examiner's manual (2nd ed.). Austin TX: PRO-ED.

[23] Roslan, N. A. A., \& Abdullah, B. (2020). Differences in the level of children gross motor skills development in Silat, Taekwondo and Karate in Malaysia. International Journal of Human Movement and Sports Sciences, 8(2), 57-62.

[24] Tseng, H. L., \& Chiu, W. H. (2008). The evolution of research on the development of children's throwing movement. Quarterly of Chinese Physical Education, 22(4), 103-109.
[25] Lin, C. L. (2007). Health-related Physical Fitness: From Theory to Practice. In Jwo JC (Eds), The Training Programs of Museular Strength and Museular Endurance (pp.3-1 3-45). Taichung city: Wagner Co. Ltd.

[26] Gansen, H.M. (2019). Push-Ups Versus Clean-Up: Preschool Teachers' Gendered Beliefs, Expectations for Behavior, and Disciplinary Practices. Sex Roles, 80, 393408.

[27] Cameron, C. E., Brock, L. L., Murrah, W. M., Bell, L. H., Worzalla, S. L., Grissmer, D., \& Morrison, F. J. (2012). Fine Motor Skills and Executive Function Both Contribute to Kindergarten Achievement. Child Development, 83(4), $1229-1244$. 